\title{
RAZÃO PÚBLICA DE RAWLS COMO RAZÃO RETÓRICA
}

\author{
RAWLS' PUBLIC REASON AS RHETORICAL REASON
}

Narbal de Marsillac ${ }^{1}$

\section{RESUMO}

O objetivo do presente texto é mostrar que a legitimação pelo procedimento e pela justificação pública aparece hoje como um verdadeiro topos (lugar-comum) de ampla aceitação que nos faz atentar para aspectos retórico-argumentativos do discurso público relacionados à própria implementação de uma sociedade democrática bem ordenada capaz de abrigar o que Rawls chamou de pluralismo razoável que a caracteriza. Para isso, o pensador americano pressupõe uma razão pública que estabeleça a impossibilidade de se ter uma única doutrina abrangente e de ter garantida a verdade inteira. Como resultado da presente abordagem, constatou-se, pelo método da releitura retórica (rhetorical rereading), que a forma e o conteúdo dessa racionalidade pública estão próximos de uma racionalidade retórica na medida em que aquela se delineia ora como deliberação argumentativa num contexto público em que se tenha a concepção mais razoável de justiça, ora como especificação intersubjetivamente ponderada dos valores políticos básicos de uma associação cooperativa fundada na reciprocidade e no compartilhamento de princípios comuns de justiça. Contribui-se, assim, com a concepção que vê esse fórum político público, composto de cidadãos livres e iguais, capazes de raciocínio público, como juízes, funcionários do executivo e do legislativo e candidatos a cargos públicos, como bons exemplos de discursos retoricamente adaptados a audiências socialmente idealizadas.

Palavras-Chave: John Rawls - Razão Retórica - Razão Pública - Releitura Retórica - Viragem Retórica

\begin{abstract}
The aim of this text is to show that legitimation by procedure and by public justification appears today as a truly widely accepted topos (common place) that makes us pay attention to rhetoricalargumentative aspects of public discourse related to the very implementation of a capable wellordered democratic society able to accept what Rawls called the reasonable pluralism that characterizes it. For this, the American thinker presupposes a public reason which establishes the impossibility of having a single comprehensive doctrine and the entire truth guaranteed. As a result of this approach, it was found, through the method of rhetorical rereading, that the form and content of this public rationality are close to a rhetorical rationality, as long as it is now delineated as an argumentative deliberation in a public context in that one has the most

\footnotetext{
${ }^{1}$ Professor Associado do Departamento de Filosofia da Universidade Federal da Paraíba - UFPB. Professor dos Programas de Pós-Graduação em Filosofia e em Ciências Jurídicas da mesma Instituição. Presidente da Sociedade Brasileira de Retórica - SBR (2019/2020). Professor visitante da Universidade Laval -UL (2016) e do Instituto de Tecnologia de Massachusetts - MIT (2019) Afiliação: Universidade Federal da Paraíba - UFPB. Lattes: http://lattes.cnpq.br/0009467518994817. Orcid:https://orcid.org/0000-0001-9663-9228. E-mail:narbal.marsillac @ academico.ufpb.br
} 
reasonable conception of justice, and sometimes as an intersubjectively weighted specification of the basic political values of a cooperative association founded on reciprocity and sharing common principles of justice. It thus contributes to the conception that sees this public political forum, composed of free and equal citizens, capable of public reasoning, such as judges, administrators and congressman and candidates for public office, as good examples of rhetorically adapted speeches to socially idealized audiences.

Keywords: John Rawls - Rhetorical Reason - Public Reason - Rhetorical Rereading Rhetorical Turn

Uma sociedade razoável não é sociedade de santos nem sociedade de egocêntricos

John Rawls

\section{Introdução}

Vários teóricos têm apontado a existência de uma viragem retórica (rhetorical turn) no coração mesmo da contemporaneidade que abriga em seu seio as mais diferentes críticas recorrentes ao estatuto da razão e do pensar em geral (VATTIMO, 2002; ANGUS \& LANGSDORF，1993; SWARTZ，1997; FRANK，2011; SILLS \& JENSEN， 1992; MAILLOUX, 1998; SCHIAPPA, 2003; MARSILLAC, 2014). Toda problemática parece orbitar em torno do que Habermas chamou de "crítica neo-estruturalista da razão" (2002a, p.1) que aponta ou denuncia o caráter pretensamente autofundante da modernidade filosófica sujeitocentrada. A questão contemporânea talvez poderia ser resumida, no dizer de Vattimo, no "abandono do ser como Grund" presente nas reflexões de Heidegger (2002, p. 182) que implicaria a constatação da ausência de "coatividade metafísica" (VATTIMO, 2002, p. 183). Ou seja, da conscientização relativamente recente da indigência de toda positividade em virtude da crise de fundamentos e do "niilismo consumado" (VATTIMO, 2002, p. 5). O pensador italiano conclui pela natureza inevitavelmente estética e retórica da verdade e da ciência (VATTIMO, 2002, p. 139). O que facilmente se constata, entretanto, é que a viragem retórica tem diferentes matizes e recepções por parte dos contemporâneos. David Frank, por exemplo, sugere existir dois tipos de viragens retóricas: uma explícita, com Kenneth Burke, Chaim Perelman e Walter Jackson Ong e uma outra implícita, com Hannah Arendt, Michael Polyani e Stephen Toulmin. Esta última é caracterizada pela problematização do papel da razão no pósguerra e da não adoção do vocabulário próprio da tradição retórica quase tão antigo quanto o da própria filosofia. Como defende Frank: 


\begin{abstract}
Arendt, Perelman, Mckeon e outros voltaram-se para a retórica porque isso os ajudou a lidar com os traumas desencadeados pela II Guerra Mundial. O choque do holocausto, o fracasso da razão ao não impedir o genocídio e a guerra, e a gigantesca quantidade de crimes contra a humanidade tornaram-se exigências primárias para os intelectuais no pós-guerra. A consequência imediata desses traumas foi a grande dificuldade para muitos entenderem o que de fato aconteceu. Depois de 13 anos do fim da II Grande Guerra, alguns pesquisadores produziram romances e trabalhos acadêmicos que tentaram superar esses traumas e, ao fazêlo, vários fizeram viragens retóricas implícitas e explícitas. O ano de 1958 parece ser o ano-chave nessa viragem e eu mostrei como Hannah Arendt, em uma viragem implícita, e Chaim Perelman, numa viragem explícita, desenharam, a partir do pensamento clássico e judeu, uma resposta retórica para a pergunta sobre a razão e a questão judaica. Um próximo passo no desenvolvimento de uma melhor compreensão da viragem retórica de 1958 é examinar a viragem retórica implícita e explícita assumida em outros trabalhos além dos trazidos por Perelman e Arendt: Personal Knowledge de Polyani, Ramus de Ong, o artigo Daedalus de Burke, Os Usos do Argumento de Toulmin e um surpreendente número de outros trabalhos publicados durante esse ano $(2011$, p.250)
\end{abstract}

Nessas linhas, questiona-se se o próprio Rawls, em virtude especificamente de seu conceito de razão pública e de sua concepção de justiça política essencialmente fundada na cooperação equitativa de todos os concernidos, também não deveria ser incluído no rol dos pensadores contemporâneos co-partícipes de uma viragem retórica implícita como quis Frank, uma vez que acordos equitativos só podem ser obtidos de forma igualmente equitativa (RAWLS, 2003, p. 74) e, nesse sentido, sem espaço para o que Vattimo chamou de "coatividade metafísica" (2002, p. 183) e não retórica. Procurar-se-á mostrar aqui que sua razão pública é razão retórica (MARSILLAC, 2011). Especialmente quando se a interpreta pelo método da releitura retórica que procura reinterpretar os textos e os discursos enquanto uma atividade comunicacional que visa um fim e é dirigido a uma determinada audiência (KRAEMER, 2017; KUZBORSKA, 2019), atentando sobretudo para as "escolhas retóricas" (KUZBORSKA, 2019, p. 3) do texto que permaneceriam ocultas numa leitura ou escuta não retórica ou mais apressada do mesmo discurso. Fundamentalmente, o método da releitura retórica se perfaz no esforço do intérprete em "construir um contexto retórico para o texto enquanto um meio de dotá-lo de sentido“ (HAAS \& FLOWER, 1988, p. 168). Assim, a releitura retórica de um discurso aliada à viragem retórica implícita servem como fonte inesgotável de reinterpretação de um autor ou de um texto que, mesmo sem fazer uso explícito do vocabulário próprio da tradição retórica, tem agora suas tópicas mapeadas, seus argumentos estruturantes e suas figuras de linguagem igualmente expostos e, com isso, explicitam-se as escolhas estratégicas e persuasivas fundamentais. 


\begin{abstract}
A argumentação é um todo, destinado a um auditório determinado. Passa-se, assim, de um problema de comunicação a uma ontologia e a uma estética, ao passo que a ordem ontológica e a ordem orgânica são apenas dois desvios de uma ordem adaptativa. As exigências da adaptação ao auditório é que devem guiar no estudo da ordem do discurso, essa adaptação atuará, quer diretamente, quer por intermédio das reflexões do ouvinte acerca da ordem. O que ele encara como ordem natural, as analogias que ele percebe com um organismo ou com uma obra de arte são apenas argumentos entre outros argumentos. O orador deverá levar isso em conta, da mesma forma que todos os fatores suscetíveis de condicionar o auditório. Método e forma poderão assumir, respectivamente, maior ou menor importância conforme se tratar de auditório particular, técnico ou universal. Mas uma teoria da argumentação que não abrangesse todos esses elementos conjuntamente sempre se afastará de seu objeto. A dissociação entre forma e fundo, que conduziu à desumanização da própria noção de método, conduziu também à acentuação do aspecto irracional da retórica (PERELMAN, 2002, p. 574)
\end{abstract}

Desde de 1971, John Rawls consagrou-se como um dos maiores teóricos da filosofia política contemporânea justamente por se esforçar em pensar o problema da justiça segundo um procedimento construtivista e, portanto, não substancial, num contexto plural e democrático que ao mesmo tempo supera o dogmatismo metafísico das posturas mais tradicionais e o utilitarismo auto sacrificial e auto derrotante (RAWLS, 2002b, p. 15; MÖLLER, 2006, p. 25). Seu esforço foi pensar a justiça a partir do que chamou de posição original (RAWLS, 2002b, p. 19) na qual haveria a divisão equitativa e apropriada entre todos os concernidos das vantagens sociais a partir dos princípios de igualdade de oportunidades para todos e da necessidade de se justificar eventuais desigualdades na medida em que beneficiem os menos favorecidos (RAWLS, 2002b, p. 25; MÖLLER, 2006, p. 26), o que caracteriza sua concepção de justiça como equidade enquanto o "equilíbrio adequado entre reivindicações concorrentes" (RAWLS, 2002b, p. 11). Análogo ao método divider-chooser ou divisor-seletor que, inspirado numa famosa passagem bíblica que fala da controvérsia entre Abraão e Lot (Gen 13), separa aquele que divide daquele que escolhe e que também está na base do princípio da divisão dos poderes (um é o que legisla, outro é o que aplica a lei e um outro é o que julga), Rawls idealizou uma situação originária onde, cegos pelo véu da ignorância a respeito de si mesmos, o que garantiria a simetria das relações mútuas (RAWLS, 2002b, p. 13), os primeiros participantes de uma associação política devem escolher, de forma ponderada (retórica?), os princípios fundamentais de justiça. Diz Rawls: “a ideia norteadora é que os princípios da justiça para a estrutura básica da sociedade são o objeto do consenso original" (2002b, p. 12). Nesse sentido, tais princípios são fruto de acordos entre iguais que independeriam de verdades necessárias e apodíticas (RAWLS, 2002b, p. 23). Entenda-se: não retóricas. É o que sugere, por exemplo, Kraemer que, a partir da releitura (retórica) dessas considerações, vê uma grande proximidade entre as 
propostas da nova retórica perelmaniana e a concepção de justiça rawlsiana (2017). O próprio Perelman teceu também comentários críticos às propostas de Rawls, diz ele: "a conclusão a que chegará um deles será também a de qualquer outro. É por essa razão que Rawls, inspirando-se no modelo do espectador imparcial, afirma que a conclusão será a mesma para qualquer homem racional, e isto sub specie aeternitatis" (1996, p. 242)

Contrariamente à crítica de Perelman à concepção de justiça de Rawls, ao fazer depender a justiça pública antes de um acordo ou contrato social hipotético original, o estadunidense parece romper com uma tradição que a entendia escorada definitivamente numa concepção conteudística, substancial e metafísica. Seu esforço foi romper com esse quadro e propor a legitimação pela discutibilidade e pelo procedimento propriamente racional. Em sua conclusão da obra de 1971, sustenta que: "não há nenhum grupo de condições ou de princípios básicos que possamos defender, de forma sensata, como necessários ou definidores da moralidade, e, portanto, como sendo especialmente adequados para carregar o ônus da prova" (RAWLS, 2002b, p. 644). Desde Aristóteles e sua obra sobre retórica (2005b), um discurso racional que não esteja fundado em princípios necessários é opinativo e inevitavelmente dialético, ou seja, tópico-retórico. Para o Estagirita, os chamados raciocínios apodíticos (nãoretóricos) só podem arvorar-se enquanto tais justamente em virtude da necessidade ou verdade incontestável e não opinativa de seu ponto de partida (ARISTÓTELES, 2005a, p. 347). Como ensina também Perelman:

\begin{abstract}
O raciocínio dialético é considerado paralelo ao raciocínio analítico, mas trata do verossímil em vez de tratar de proposições necessárias. A própria ideia de que a dialética concerne a opiniões, ou seja, a teses às quais se adere com uma intensidade variável, não foi aproveitada. Dir-se-ia que o estatuto do opinável é impessoal e que as opiniões não são relativas aos espíritos que a elas aderem. Em contrapartida, essa ideia de adesão e de espíritos ao quais se dirige um discurso é essencial em todas as teorias antigas de retórica. Nossa aproximação desta última visa a enfatizar o fato de que é em função de um auditório que qualquer argumentação se desenvolve. O estudo do opinável dos Tópicos poderá, nesse contexto, inserir-se em seu lugar $(2002$, p. 5)
\end{abstract}

Por isso, aquele que se usa do discurso depende do acordo prévio a respeito das premissas sobre as quais vai justificar sua tese e, neste sentido, o discurso será tanto mais persuasivo quanto mais é capaz de espelhar as opiniões de aceitação geral ou topoi do interlocutor. Portanto, seguindo esse vocabulário propriamente retórico e relendo retoricamente o filósofo norteamericano, fica fácil perceber que sua proposta corresponde perfeitamente ao que David Frank chamou de viragem retórica implícita. O que enriquece e reatualiza de forma extraordinária seus escritos e confirma o caráter retórico de sua racionalidade pública. 
O silogismo é um discurso argumentativo no qual, uma vez formuladas certas coisas, alguma coisa distinta destas coisas resulta necessariamente através delas pura e simplesmente. $\mathrm{O}$ silogismo é demonstração quando procede de premissas verdadeiras e primárias ou tais que tenhamos extraído o nosso conhecimento original delas através de premissas primárias e verdadeiras. O silogismo dialético é aquele no qual se raciocina a partir de opiniões de aceitação geral (ARISTÓTELES, 2005a, p. 347)

Nessa linha de raciocínio, no presente texto abordar-se-á aqui, em um primeiro momento, o relevante papel que a retórica e a persuasão que lhe é correlata cumprem no pensamento contemporâneo caracterizado pela pluralidade e co-existência, num mesmo espaço e num mesmo tempo, de perspectivas distintas que se por um lado impossibilitam a permanência da metafísica tradicional que recusa a diversidade (HABERMAS, 2002b, p. 153) e a postulação e defesa de uma única compreensão monomítica daquilo que há e do que deve haver (HABERMAS, 2002b, p. 169), por outro lado, demanda por novos processos discursivos de legitimação racional do saber (LYOTARD, 2004, p. 51). Num segundo momento, tratar-seá justamente da inevitabilidade dessa mesma pluralidade e da racionalidade retórica que viceja em meio à diversidade e é a única capaz de lidar com o diferente em sua outridade e incluí-lo. Logo em seguida, defender-se-á o caráter retórico da racionalidade pública rawlsiana, opondo essa constatação ao conceito clássico de erística na qual, ao contrário da retórica, há um desprezo pelo interlocutor e se visa exclusivamente a manipulação discursiva. E, por fim, tratarse-á das questões que envolvem a legitimidade política e como, num contexto democrático e de pluralismo razoável, tal legitimação passa a depender da inclusão inerente à perspectiva retórica e do esforço em superar a polarização política própria de posicionamentos erísticos.

\section{Retórica e Persuasão na Contemporaneidade}

Qualquer um hoje que se dedique a pensar o próprio pensamento, sustenta Lempereur, vai ficar provavelmente dividido entre uma aceitação passiva dos dados que nos vêm do mundo e como refletimos sobre eles ou uma rejeição (pelo menos, uma desconfiança) dessas informações e de suas ponderações e pressuposições correspondentes (1990, p. 9; SANTAYANA, 2003: RORTY, 1991). O que nos faz oscilar entre um positivismo ingênuo que parte da suposta obviedade do evidente e um ceticismo exagerado que nos condena a um relativismo moral e epistêmico. A perda dos fundamentos únicos num contexto cada vez mais reconhecidamente plural, globalizado e multicultural, diz ele, configura-se numa espécie de 
naufrágio contemporâneo da filosofia que, paulatinamente, converte-se em nada mais do que um outro tipo de literatura. Nesse mesmo sentido, considerando a própria ontologia como um "retorno recalcado sofístico", Cassin vai apontar o caráter discursivo e performático do "efeito mundo" ou "l'effet monde" (2005, p. 8), fazendo com que "descrições objetivadoras migrem para o mundo da vida" (HABERMAS, 2002, p. 183). A saída ressentida de filósofos que teimam em manter-se no seu nobre ofício de pensar o pensar e que se sentem menos por serem vistos agora como escritores ou romancistas, ou ainda, como historiadores das ideias, é a tentação logicista por um lado, que recusa rediscutir seus pressupostos e insiste dogmaticamente em vê-los como necessários e incorrigíveis, e a tentação niilista, que se opõe, muitas vezes de forma irresponsável, a toda possibilidade de pretensão racional. Como quis o pensador belga: "Está distante o tempo em que a filosofia pretendia senão tudo explicar, ao menos, tudo questionar" (LEMPEREUR, 1990, p. 7). A saída parece se encontrar no meio termo, naquilo que os antigos e, mais precisamente, Platão, chamaram de rhetoriqué (SCHIAPPA, 1991). Surgida no século V a.C, a retórica sempre se caracterizou como um peithous demiourgós (NIETZSCHE, 1995, p. 30) ou uma criadora de persuasão que parece se imiscuir em tudo que fazemos, em tudo que somos e na própria forma como percebemos o mundo e a nós mesmos (MARSILLAC, 2021). Como também defende Burke "não há persuasão sem retórica, nem sentido sem persuasão" (1997, p. 172). Aristóteles a define como "a arte de encontrar em cada contexto concreto o que é mais persuasivo" (Rhet 1356a; 2005b, p. 96) e como raciocínio dialético ou não apodítico que consiste no silogismo que parte de premissas contingentes e amplamente aceitas conhecidas como topoi ou lugares comuns (ARISTÓTELES, 2005a, p. 349). Sua mais clara feição se caracteriza pelo caráter adaptativo dos discursos que sempre são forjados a partir da antecipação, por parte do orador, dos principais elementos que, segundo ele, compõem sua audiência. O que faz do bom orador aquele que melhor consegue suprir a distância natural entre um auditório presumido e o auditório real (PERELMAN, 2002, p. 22). Mas o importante a frisar é que, na perspectiva retórico-discursiva, não há nem aceitação passiva dos dados nem sua rejeição, mas adaptação às premissas dos que irão ouvir ou ler o referido discurso.

A teoria da argumentação não se pode desenvolver se toda prova é concebida como redução à evidência. Com efeito, o objeto dessa teoria é o estudo das técnicas discursivas que permitem provocar ou aumentar a adesão dos espíritos às teses que se lhes apresentam ao assentimento. O que caracteriza a adesão dos espíritos é sua intensidade ser variável: nada nos obriga a limitar nosso estudo a um grau particular de adesão, caracterizado pela evidência, nada nos permite considerar a priori que os graus de adesão a uma tese à sua probabilidade são proporcionais, nem identificar evidência e verdade, e sim estudá-los separadamente, nem que seja para preocupar-se posteriormente com sua 
interferência ou com sua correspondência eventuais. Somente com essa condição é que é possível o desenvolvimento de uma teoria da argumentação de alcance filosófico (PERELMAN, 2002, p. 4)

Habermas critica essa postura retórica alegando que tal adaptação do orador ao seu auditório implicaria a impossibilidade de se separar, com clareza, validade de aceitabilidade e, com isso, verdade, justiça e valores éticos ou morais dependeriam mais da "habilidade retórica ou da força física" do que propriamente dos procedimentos racionais e argumentativos (HABERMAS, 2016, p. 68). Diante de uma assembléia composta de nazistas, por exemplo, caberia ao falante/escritor também acolher e, neste sentido, adaptar-se a tais pressupostos comuns de intolerância, de exclusão e de violência. Mas, na verdade, todos os nossos discursos são retóricos porque, persuasivamente dotados de sentido, estão sempre adaptados a audiências reais ou imaginadas. Na prática, costumamos nos dirigir ou nos adaptar àquelas premissas que já previamente nos persuadiram no passado, o que limita o âmbito daqueles auditórios para os quais poderíamos eventualmente proferir um discurso efetivamente persuasivo. A persuasão depende fundamentalmente do apreço do orador pela adesão do seu interlocutor (PERELMAN, 2002, p. 18) E, portanto, o freio moral já está dado na própria ausência de adaptação a auditórios considerados pelo orador como imorais ou injustos e, nesse sentido, que não foram capazes de persuadi-lo previamente. Como se disséssemos que é nazista o que profere discurso persuasivo para uma audiência igualmente nazista, já que não poderia fazê-lo da mesma forma, ou seja, persuasivamente, dirigindo-se agora a um auditório democrático, inclusivo e tolerante. Perelman resumiu bem essa situação quando defendeu que cada auditório tem o orador que merece (2002, p. 18). Diz ele: “é por essa razão que, em matéria de retórica, parece-nos preferível definir o auditório como "o conjunto daqueles que o orador quer influenciar com sua argumentação" (2002, p. 22).

\section{Racionalidade Retórica, Pluralismo e Alteridade}

O reaparecimento contemporâneo da retórica antiga que ficou conhecido como viragem retórica e o que chamou-se aqui de releitura retórica estão relacionados à ascensão, ainda relativamente recente, do pluralismo em qualquer uma de suas formas gerado sobretudo pela sofisticalização crescente dos meios e tecnologias de comunicação. É essa pluralidade gradativa que aprimora cada vez mais o nosso senso crítico por revelar o caráter sempre circunscrito e paroquial dos pressupostos do pensar em geral (PERELMAN, 1993, p. 54). Entretanto, se não se pode mais pretender universalidade, uma vez que "valores universais não são senão 
instrumentos de persuasão" (PERELMAN, 1993, p. 46), saberes definitivos ou metanarrativas, como também quis Lyotard (2004), não se deve igualmente abandonar toda esperança de justificação racional para o que se postula. Como muito bem defende Vattimo, "a experiência contemporânea de verdade é estética e retórica" (2002, p. 139), querendo com isso pontuar o caráter indigente de toda positividade e a perda da força vinculante do discurso metafísico (HABERMAS, 2002, p. 166). Curiosamente é de Rawls a tese segundo a qual "questões fundamentais em filosofia não se resolvem com argumentos conclusivos" (1995, p. 71). E ele tem razão! Não podemos pular para fora de nossas condicionalidades e pretender sustentar, de forma definitiva, uma determinada tese supostamente incondicionada e divorciada do lugar histórico, social e cultural do qual pensamos (HABERMAS, 2002, 167) porque "a consciência histórica reconhece sua provincialidade em relação ao futuro" (HABERMAS, 2002, 166). Novamente Vattimo esclarece que "a antropologia nutre fundadas suspeitas acerca do caráter ideológico do ideal de um encontro com culturas radicalmente outras" (2002, p. 158). Falando do advento da pós-modernidade em filosofia e da esperança de ainda se ter hoje uma única verdade que poderia unificar e dirimir a precariedade de toda objetividade e pôr fim ao pluralismo, Vattimo sustenta que:

\begin{abstract}
A noção de verdade não mais subsiste e o fundamento não mais funciona, dado que não há fundamento algum para crer no fundamento, isto é, no fato de que o pensamento deva "fundar": não se sairá da modernidade mediante uma superação crítica, que seria um passo ainda de todo interno à própria modernidade. Fica claro, assim, que se deve buscar um caminho diferente. É esse momento que se pode chamar de nascimento da pós-modernidade em filosofia, um acontecimento cujos significados e cujas consequências, assim como os da morte de Deus anunciada no aforismo 125 da Gaia Ciência, ainda não acabamos de medir
\end{abstract}

A retórica, portanto, e mais precisamente a releitura retórica (JARRAT, 1991: KUZBORSKA, 2019; HAAS \& FLOWER, 1988) se configuram hoje num dos meios mais adequados de preservar um teor retórico-racional em meio à controvérsia e ao caos próprio de um niilismo consumado desvelado pela inscrição permanente do outro enquanto outro que chamamos globalização (BAUMAN, 1999). E quem é o outro enquanto outro? O outro enquanto outro é o outro que não nos espelha e, assim, não detém conosco nenhuma identificação narcísica. Rorty os chama de "pessoas perturbadoramente diferentes" (2005, p. 93). Aproximando-se de Vattimo, Dupréel ensina que a morte de Deus nietzscheana é a morte do Deus-Necessidade ou Le Dieu-Necessité (1990, p. 19; PLEBE, 1992, p. 40), ou seja, é a perda do primado da evidência que se revela agora como legitimadora de uma relação silenciosamente violenta, porque, partindo-se arretoricamente de certezas pressupostas e 
infundadas, gerou-se, ao longo dos séculos, muita humilhação, sofrimento, exclusão, desrespeito e, com isso, perpetuou-se um estado de assujeitamento e de crueldade permanente. Era evidente no passado, por exemplo, que o homem é superior à mulher, que o branco é superior ao negro, que o heteroafetivo é superior ao homoafetivo, que o europeu é superior ao africano, que o conhecimento científico é superior ao artístico e poético, que as ciências físicomatemáticas são superiores às humanas, que a lógica é superior à retórica, e assim por diante. Abandonamos, com isso, a verdade? Não, há verdade enquanto verossimilhança, ou seja, "verdade agora despojada das características autoritárias da evidência metafísica" (VATTIMO, 2002, p. 71). A retórica, assim, reaparece denunciando que pensar é pensar pressupostos e pensar pressupostos demanda pensar os pressupostos do próprio pensar que pensa pressupostos, indefinidamente. $\mathrm{O}$ triunfalismo de um tipo de racionalidade não retórica pretensamente parrética (parrhesia) que chega até nós e que Plebe definirá como despotismo lógico (1992, p. 53; TOULMIN, 2006, p. 253) oculta o caráter de escolha e de decisão por detrás de toda teoria e suas pressuposições (SANTAYANA, 2003, p. 22) e imuniza princípios contra a crítica futura. Como bem sustenta Nietzsche no aforismo 6 de seu Além do Bem e do Mal, toda filosofia é confissão pessoal de seu autor (2005), ou seja, é discurso comprometido com suas crenças fundamentais inconfessas ou preconceitos que, na reflexão teorética, seriam supostamente legitimadas pela racionalização. Quando fala do alcance daquela que chamou de Nova Retórica, Perelman ensina que:

\begin{abstract}
Mas a nova retórica, em oposição à antiga, diz respeito aos discursos dirigidos a todas as espécies de auditórios, trate-se duma turba reunida na praça pública ou duma reunião de especialistas, quer nos dirijamos a um único indivíduo ou a toda humanidade; ela examinará inclusivamente os argumentos que dirigimos a nós mesmos, aquando duma deliberação íntima. Considerando que o seu objeto é o estudo do discurso não-demonstrativo, a análise dos raciocínios que não se limitam a inferências formalmente corretas, a cálculos mais ou menos mecanizados, a teoria da argumentação concebida como uma nova retórica (ou uma nova dialética) cobre todo o campo do discurso que visa convencer ou persuadir, seja qual for o auditório a que se dirige e a matéria a que se refere (1993, p. 24)
\end{abstract}

Assim, afastados da premissa segundo a qual validade é sinônimo de validade formal (TOULMIN, 2006, p. 222) e razão sinônimo de verdade necessária (LEMPEREUR, 1990, p. 9), que Stephen Toulmin qualificou, como um todo, de paradigma analítico (2006, p. 222), entramos no reino de uma nova racionalidade retórica que é capaz de prosperar em meio ao pluralismo e que vê neste a expressão de um pensar menos obcecado pelo conceito enquanto meio de revelação positiva de mundo e de nós mesmos e mais enquanto estratégia retórico- 
persuasiva de manipulação ideológica e de naturalização das descrições e prescrições (SCHIAPPA, 2003). Nesse sentido, razão retórica aqui se configuraria na permanente possibilidade de aferição e ponderação intersubjetiva da validade dos pressupostos e dos meios discursivos de obtenção da anuência. É a razão retórica que explicita as bases retóricas inconfessas da razão tradicional. Ou seja, retórica e análise retórica são indiscerníveis. Como se costuma dizer: aprender a montar é aprender a desmontar. Ao aprender a apertar um parafuso, aprendemos concomitantemente a desapertá-lo. Aprender os meios de elaboração retórica de um discurso persuasivo é aprender a criticá-lo, justamente pela ex-posição de suas estratégias retóricas. Como também ensina Plebe (1992, p. 6), "ars ars celare", a força persuasiva da arte está em seu ocultamento. Nesse sentido, a retórica é tanto mais poderosa quanto menos é percebida enquanto tal. O nazista Paul Joseph Goebbels dizia que "não há forma mais efetiva de persuasão do que quando não se está ciente de que se está sendo persuadido”. Estudamos os processos persuasivos para justamente não sermos ou permanecermos inconscientemente sendo persuadidos. Apesar de inevitável, caberia à crítica retórico-filosófica explicitar e expor as inúmeras persuasões inconscientes que arrastam nosso espírito e nos assujeitam (MARSILLAC, 2021, p. 15). E, pelo caráter epidítico desses discursos, perpetua-se esse estado pela retórica da naturalização que mantém sua força persuasiva enquanto não é objeto de uma análise retórica subsequente. Santayana vai chegar a falar de um supernaturalismo (2003, p. 153). Mas a verdade é que não há crítica sem insubordinação, indocilidade e produção de desfamiliaridade. No entanto, em geral, nossas reflexões supostamente críticas são obedientes, dóceis e comuns. Falta-nos análise retórica! Ou seja, falta-nos identificar os processos retóricopersuasivos dos discursos que se quer analisar. Sem essa prática, não há crítica nem democracia. $\mathrm{Na}$ verdade, esta última sem o ensino da retórica e da análise retórica que lhe é correlata se converte em demagogia.

\section{Erística e Razão Pública Retórica}

$\mathrm{Na}$ esteira do que chamou-se aqui de releitura retórica, inspirados sobretudo pelos trabalhos de Jarrat (1991), que a aplica à sofística; de Schiappa (1991), que a adota quando expõe o uso por Platão da técnica retórica da dissociação de noções ao criar o termo rhetoriké e distanciar sua filosofia da sofística; de Kuzborska (2019); e de Haas \& Flowers (2019), a proposta é compreender a razão pública em Rawls como razão retórica. Ler retoricamente um texto ou autor consiste, como vimos, em expor e circunscrever seus pressupostos e em desvelar 
as retóricas ocultas dos discursos, não para invalidá-los, mas para limitar a auditórios históricos específicos o alcance de sua validade por meio de uma epoché retórica ou suspensão retórica dos juízos (MARSILLAC, 2021, p. 6). Segundo o pensador americano, as bases públicas de justificação sobre questões políticas fundamentais devem ser aceitas enquanto tais por todos os cidadãos (RAWLS, 1995, p. 19; QUONG, 2014). Compõem, portanto, o campo do nãonecessário que Dupréel faz referência (1990, p. 19) e que coincide com o da retoricidade. Diferentemente da erística (SCHOPENHAUER, 2014), a retórica reconhece o caráter razoável do discordante. A primeira visa a vitória independentemente do processo dialógico, propriamente dito, desdenha da verdade dos juízos e se inscreve no debate "pro ara et focis" (por nossos altares e lares ou pelo que nos é mais caro, ou seja, por interesse pessoal) e "per fas et nefas" (por meios lícitos ou ilícitos). A retórica antes sobrepesa reciprocamente os argumentos, divorciando-se do monólogo e da imposição de uma determinada perspectiva e da violência. Parafraseando Ballweg, da retórica nenhum diálogo escapa (1991). Não seria diferente com o debate político. Desde 1971, Rawls pensou a justiça política a partir do que chamou de posição original, como se viu na introdução dessas linhas, e que ocuparia lugar análogo ao do Estado de Natureza do contratualismo clássico. Nessa condição hipotética, os futuros partícipes de uma mesma agremiação social, sob o véu da ignorância, decidiriam a respeito dos princípios de justiça política que deveriam reger a vida do grupo. Como não faz sentido pensar os debates da posição original permeados exclusivamente de monólogos erísticos entrecortados e de disputas narcísicas e egocentradas, também não faz sentido pensálos sem retórica e sem ponderação recíproca de razões.

\begin{abstract}
Abordando agora a dificuldade particular que se refere ao consenso sobre as condições razoáveis, devemos salientar que um dos objetivos da filosofia moral é buscar bases possíveis para acordos, onde nenhum acordo parece existir. Ela deve tentar estender o alcance de algum consenso existente e submeter à nossa consideração concepções morais mais discriminatórias. Os fundamentos da justificativa não estão prontos à nossa disposição: precisam ser descobertos e adequadamente expressos, algumas vezes por intuições felizes, outras através da observação das exigências teóricas. É tendo em mente esse objetivo que as várias condições impostas à escolha de princípios primeiros são reunidas na noção da posição original. A ideia é a de que, reunindo um número suficiente de restrições razoáveis numa única concepção, ficará óbvio que uma entre as alternativas propostas deverá ser preferida. Gostaríamos que a superioridade de uma visão particular (entre as que atualmente conhecemos) fosse o resultado, talvez inesperado, desse consenso novamente observado (RAWLS, 2002b, p. 648)
\end{abstract}

Nesse sentido, fica fácil perceber que, pela análise e releitura retórica, um primeiro comprometimento se dá aqui. Tais debates hipotéticos originários não poderiam consistir em 
simples cálculos matemáticos e apodícticos por um lado, mas também não se configuram como disputas erísticas arbitrárias. E, se são retóricos, quais os topoi ou pressupostos implícitos estariam em jogo? A decisão sobre os princípios de justiça política deveria ser precedida pela estipulação comum entre os contratantes dos critérios sobre a própria decisão. Ou seja, caberia decidir antes como iriam decidir, e assim por diante. Ou dizendo de outra forma, é de Aristóteles a tese de que não se pode raciocinar sem premissas (Rhet 1359a). Portanto, se os primeiros contratantes na posição original não raciocinam a partir de premissas necessárias autoevidentes, caso contrário, sequer haveria a necessidade do debate, mas de simples cálculos lógicos, também é verdadeiro afirmar que eles não decidiriam arbitrariamente, caso contrário, não haveria qualquer possibilidade de reconhecer o caráter de razoabilidade para as decisões. Conclui-se, assim, que retoricizam. Mas se o fazem, dependem, por sua vez, dos topoi ou pressupostos amplamente aceitos ou comuns que os vinculariam a uma determinada comunidade ou lugar, mas que, em virtude do véu da ignorância, desconhecem. O problema que aparece aqui diz respeito ao caráter excessivamente abstrato do contratualismo rawlsiano de Uma Teoria da Justiça de 1971 e que foi apontado em textos posteriores pelo próprio Rawls (1995) que vai chegar a dizer que "o liberalismo político considera essa sociedade como impossível “ (RAWLS, 2004, p. 234). A releitura retórica da constatação ralwsiana relembra o que o Estagirita chamava de argumentos abstratos, dizia ele: "abstratos são os argumentos que excluem o 'quando' e o 'como'" (Rhet 1402a; 2005b, p. 233). E o caráter essencialmente democrático da razão pública (RAWLS, 1995, p. 204; RAWLS, 2004, p. 171) que ele define como: "a razão de cidadãos em pé de igualdade que, como corpo coletivo, exercem o poder político final e coercivo uns sobre os outros, ao por em vigor as leis e ao fazer emendas a sua Constituição" (RAWLS, 1995, p. 205), não se consubstancia alheio ao próprio pluralismo razoável de sociedades democráticas concretas. Nesse sentido, quando se debate sobre perguntas políticas fundamentais, os cidadãos, livres e iguais, "precisam considerar que tipos de razões podem oferecer razoavelmente um ao outro" (RAWLS, 2004, p. 174) independentemente de uma "verdade inteira" e o zelo que a quer incorporar à vida comum (RAWLS, 2004, p. 175). Longe da exclusividade de doutrinas abrangentes, morais, filosóficas ou religiosas específicas, o que torna pública essa racionalidade é tratar de questões de justiça política fundamental e de exigir as mesmas formas de justificativas públicas (RAWLS, 2004, p. 177). Ainda que haja divergências nessas sociedades concretas atravessadas pelo pluralismo de convicções irredutíveis e que o pensador americano procura solucionar através do conceito de consenso sobreposto (RAWLS, 2003, p. 44; RAWLS, 2002, p. 243), ele ainda pensa poder 
existir uma aceitação por parte de todos os cidadãos de uma razoabilidade mínima. O que, mais uma vez, nos afasta da lógica e sua pretensão de univocidade, e da erística e seu desprezo pelo recalcitrante, inserindo sua reflexão, ainda que de forma inconsciente e desavisada, naquela viragem retórica implícita que Frank faz referência (2011, p. 240) e no "Império Retórico", como Perelman o chamará (1993), reino em que governa absoluta a dialogicidade e o respeito recíproco por todos os concernidos.

\section{Legitimidade Política, Inclusão e Polarização}

Nessa releitura retórica da razão pública de Rawls como razão retórica fica fácil perceber que o critério de legitimidade política fundado na reciprocidade e que exige que se esteja intimamente convencido pelas razões que se quer convencer (RAWLS, 2004, 181) nos remete quase que imediatamente ao conceito de auditório universal de Perelman (2002, p. 34; HABERMAS, 2016, p. 63; KRAEMER, 2017), um auditório idealizado enquanto uma assembléia hipercrítica que inexiste de fato (PERELMAN, 2002, p. 35), mas que serve como critério de razoabilidade dos discursos em geral porque, na medida em que o orador está também incluído nessa audiência ideal, ele precisa estar persuadido pelas razões que se usa para persuadir (PERELMAN, 2002, p. 537), o que exclui toda possibilidade de uso erístico e manipulador da retórica. Toda sorte de violência e exclusão consistem na impossibilidade de satisfazer esse critério que é o fundamento da razão pública. Se, no debate político, veta-se a participação de algum cidadão por razões aplicáveis a ele, mas que não seriam aplicáveis aos que o excluíram, fica claro perceber, pelo argumento de reciprocidade, que se decidiu arbitrariamente e de forma não legítima. Como exemplifica Rawls:

Quais razões podem satisfazer o critério de reciprocidade e, ao mesmo tempo, justificar que seja negada a algumas pessoas a liberdade religiosa, que outras sejam tratadas como escravas, que uma qualificação por propriedade seja imposta ao direito de voto, ou que o direito de sufrágio seja negado às mulheres? (RAWLS, 2004, p. 182)

O uso da razão pública se configura, assim, inevitavelmente como inclusivo, deliberativo, bem ordenado e dialógico. Ou seja, numa única palavra, retórico! Nesse sentido, seria contraditório pensar uma razão pública excludente, impositiva, autoritária e monológica. Quando isso ocorre, revela-se uma privatização do debate público e o crescimento do uso opressivo das Instituições e, por conseguinte, da diminuição do pluralismo. A polarização 
política, assim caracterizada, emerge tanto mais ressentida quanto mais incapaz de oferecer razões. É a vitória da erística e da permanente desqualificação de quem pensa diferente e que coincide com a morte da deliberação política e da democracia, da retórica e do diálogo, da razão pública e da própria legitimidade política, que passam a ser substituídos por uma ou mais doutrinas abrangentes específicas, morais, religiosas ou filosóficas, que, por motivos ideológicos infundados, não reconhecem a razoabilidade dos outros posicionamentos. Em contrapartida, reforçar o debate público de uma razão pública intensifica a inclusão e participação de todos os envolvidos em torno de um tema publicamente relevante para todos e todas e que demanda diálogos retóricos intensos e duradouros que densificam a cidadania e a democracia.

\begin{abstract}
A democracia tem uma longa história, desde o seu início na Grécia clássica até o presente, e há muitas ideias diferentes de democracia. Aqui, estou interessado apenas em uma democracia constitucional bem ordenada - um termo que usei no início - compreendida também como uma democracia deliberativa. A ideia definitiva a favor da democracia deliberativa é a ideia da própria deliberação. Quando deliberam, os cidadãos trocam pontos de vista e debatem as razões que os sustentam no que diz respeito a questões políticas públicas. Eles supõem que suas opiniões políticas podem ser revistas por meio da discussão com outros cidadãos, e não são, portanto, simplesmente o resultado fixo dos seus interesses privados ou não-políticos. Nesse ponto a razão pública é crucial, pois caracteriza o raciocínio dos cidadãos quanto a elementos constitucionais essenciais e questões de justiça básica (RAWLS, 2004, p. 182. Nosso grifo)
\end{abstract}

A razão pública, assim, é tanto mais pública quanto mais é retórica, dialógica e deliberativa. Se ganha contornos ideológicos, converte-se em mera disputa erística e, portanto, torna-se incapaz de revisitar-se a si mesma. Descrente da força persuasiva dos próprios fundamentos, quer agora impor-se ideologicamente usando-se do mesmo vocabulário anterior, como uma roupagem alheia que lhe traveste os verdadeiros propósitos e intenções. Chama debate ou diálogo político o que, na verdade, é monólogo e imposição dogmática e autoritária. E por política entende o que, na prática, é assujeitamento, violência e exclusão. Aristóteles nos ensina que não se debate sobre fins, mas sobre meios (1996, p. 155). O uso recorrente desses fins na argumentação pública como Pátria ou Patriotismo, Nação, País, Bem Comum, "O melhor para todos", ou simplesmente, Partido, como nas maravilhosas distopias de Orwell, é sintoma de efeito manipulatório da comunicação em geral que, pela exaltação da nobreza dos fins aventados, visa camuflar e esconder a baixeza dos meios, massificando mentes em torno de ideais comuns que passam a funcionar como verdadeiras bandeiras ideológicas içadas diante de exércitos inimigos, detestáveis e odiados. Quanto mais rancor e cólera os discursos conseguem suscitar contra aqueles que supostamente desprezam esses ideais comuns, mais são 
capazes de cegar e impedir o exercício crítico inerente ao fazer propriamente político. Bem diferente disso, ensina Rawls que

\begin{abstract}
Há três elementos essenciais na democracia deliberativa. Um é uma ideia de razão pública, embora nem todas as ideias de tal tipo sejam as mesmas. Um segundo elemento é uma estrutura de instituições democráticas constitucionais que especifique o cenário dos corpos legislativos deliberativos. O terceiro é o conhecimento e o desejo dos cidadãos em geral de seguir a razão pública e concretizar o seu ideal na conduta política. As implicações imediatas desses elementos essenciais são o financiamento público de eleições e o provimento de ocasiões públicas para a discussão ordenada e séria de questões fundamentais e de questões de política pública. A deliberação pública deve ser possível, reconhecida como característica básica da democracia, e livre da maldição do dinheiro. Do contrário, a política é dominada por interesses corporativos e outros interesses organizados, que através de grandes contribuições para as campanhas eleitorais distorcem, quando não excluem, a discussão e a deliberação públicas (RAWLS, 2004, p. 183)
\end{abstract}

Aristóteles postula que corajosos não desprezam (Rhet 1380a). O verdadeiro diálogo político inerente a uma racionalidade pública e retórica demanda a coragem daqueles e daquelas que estão dispostos a abandonar suas certezas e convicções em nome dos melhores argumentos apresentados no "fórum político público" (RAWLS, 2004, p. 176), usando-se para tal do critério de reciprocidade pela ponderação mútua e efetiva das propostas consideradas mais razoáveis. É uma verdadeira "amizade cívica" (RAWLS, 2004, p. 18) que impede a manipulação erística e acovardada dos debates nos quais quer ser bem sucedida pela reprodução à exaustão, através dos meios digitais de comunicação, de fake news e da apresentação enviesada de dados e de narrativas históricas grosseiramente revisitadas, numa clara aplicação do princípio segundo o qual "quem domina o passado, domina o futuro. E quem domina o presente, domina o passado" de Orwell em sua obra 1984. Polarização política traduz, assim, fundamentalmente um desequilíbrio dos valores políticos fundantes de um determinado grupo social e a emergência de uma inimizade cívica que quer se impor covardemente não pela via do diálogo retórico, da democracia deliberativa e da razão pública, mas pelo desprezo e intolerância para com aqueles e aquelas que pensam de forma diferente no "grande jogo da política" (RAWLS, 2004, p. 184), uma vez que

A razão pública nos pede que o equilíbrio dos valores que consideramos razoáveis em determinado caso seja um equilíbrio que sinceramente pensemos que os demais também considerem razoável. Ou, se isto não é possível, que pensemos que o equilíbrio de valores possa ser considerado ao menos não desarrazoado, nesse sentido: quem quer que se oponha a nossos valores possam entender, não obstante, como as pessoas razoáveis podem subscrever este equilíbrio de valores. Isto conserva os nexos de amizade cívica e coincide com o dever da civilidade. Em algumas questões, é o melhor que podemos fazer (RAWLS, 1996, p. 239) 


\title{
Conclusão
}

A viragem retórica implícita e a releitura retórica, assim, trazem uma nova compreensão para o pensamento de Rawls e para sua concepção de justiça como equidade que ele mesmo reconhecia em 1971 não ser convincente para todos (RAWLS, 2002, p. 17), revitalizando suas propostas pela caracterização inegavelmente retórica da racionalidade pública que subjaz por detrás de seu projeto. Ao privilegiar o consenso, o debate e a deliberação e escolha racional e ponderada entre iguais, o pensador americano delineou, com seus próprios termos, as bases retóricas e essencialmente dialogais de sua reflexão. Como Arendt também que nada fala de retórica, mas vincula o seu oposto ao surgimento do totalitarismo que tanto critica e, por isso, promove uma viragem retórica implícita, em Rawls, como vimos aqui, parece ocorrer o mesmo, uma vez que o espaço dado em seu pensamento ao consenso e à ponderação recíproca das razões no processo de legitimação política da justiça pública revela seu primordial apreço pelo debate e pelos processos de ponderação das razões. Quando fala das relações entre ideologia e terror, Arendt talvez tenha feito, sem sequer citar a retórica, uma de suas mais persuasivas defesas

\begin{abstract}
O expediente que ambos os governantes totalitários usaram para transformar suas respectivas ideologias em armas, com as quais cada um dos seus governados podia obrigar-se a entrar em harmonia com o movimento do terror, era enganadoramente simples e imperceptível: levavam-nas mortalmente a sério e orgulhavam-se, um, do seu supremo dom de "raciocínio frio como gelo" (Hitler), e o outro, da "impiedade da sua dialética", e passaram a levar as implicações ideológicas aos extremos da coerência lógica que, para o observador, pareciam despropositadamente "primitivos" e absurdos: a "classe agonizante" consistia em pessoas condenadas à morte; as raças "indignas de viver" eram pessoas que iam ser exterminadas. Quem concordasse com a existência de "classes agonizantes" e não chegasse à consequência de matar os seus membros, ou com o fato de que o direito de viver tinha algo a ver com a raça e não deduzisse que era necessário matar as "raças incapazes", evidentemente era ou estúpido ou covarde. Essa lógica persuasiva como guia da ação impregna toda estrutura dos movimentos e governos totalitários (1990, p. 676)
\end{abstract}

Igualmente Rawls defende a retórica sem citá-la quando sustenta que não pretende “dizer que o razoável constitui o todo da sensibilidade moral, mas inclui a parte que se conecta com a ideia da cooperação social justa" (1995, p. 69) ou quando sustenta que "considerar um desastre o pluralismo razoável é considerar também que é um desastre o exercício da razão em condições de liberdade" (1995, p. 18) ou quando simplesmente postula o que chamou de fato do pluralismo e da possibilidade de coexistência pacífica e respeitosa, numa mesma associação política, de diferentes doutrinas abrangentes, de concepções de bem e de vida boa pela limitação 
do que valoramos ao campo político (RAWLS, 1995, p. 201), diz ele: “a concepção política pode obter nossa anuência inicial mais profundamente, independentemente das nossas doutrinas abrangentes e antes que se suscitem conflitos com essas doutrinas" (RAWLS, 1995, p. 201). Querendo, com isso, justamente salvaguardar um mesmo fórum público de debate político que independeria das opções ideológicas individuais, impedindo e limitando, em última instância, a possibilidade de imposição desequilibrada e opressiva de valores de determinadas pessoas ou grupos. O que coaduna de forma surpreendentemente precisa com os ideais retóricos e democráticos de tempos imemoriais.

\section{Referências Bibliográficas}

ANGUS, I. \& LANGSDORF, L. The critical turn: rhetoric and philosophy in postmodern discourse. Carbondale and Edwardsville: Southern Illinois University Press, 1993.

ARENDT, H. Origens do Totalitarismo. Tradução de Roberto Raposo. São Paulo: Ed. Schwarcz, 1990

ARISTÓTELES. Ética a Nicômaco. São Paulo; Ed. Nova Cultural, 1996

ARISTÓTELES. Órganon. Tradução de Edson Bini. Bauru: Edipro, 2005ª

ARISTÓTELES. Retórica. Tradução de Manuel Alexandre Júnior. Lisboa; Ed. Imprensa NacionalCasa da Moeda, 2005b

BALLWEG, O. Retórica Analítica e Direito. Revista Brasileira de Filosofia, vol. XXXIX, 1991

BAUMAN, Zigmunt. Globalização: As Consequências Humanas. Tradução de Marcus Penchel. Rio de Janeiro: Ed. Zahar, 1999

BURKE, K. A rhetoric of motives. Berkeley: University of California Press, 1997

CASSIN, B. O Efeito Sofístico: Sofística, Filosofia, Retórica, Literatura. Tradução de Ana Lúcia de Oliveira e Maria Cristina Franco Ferraz

FRANK, D. 1958 and the rhetorical turn in 20th-Century thought. Review of Communication, 11: 4, 2011, pp. 239-252

HAAS, C. \& FLOWER, L. Rhetorical reading strategies and the construction of meaning. College Composition and Communication, Vol. 39. No. 2, 1988, pp. 167-183

HABERMAS, J. Teoria do Agir Comunicativo. tradução de Paulo Astor Soethe. São Paulo: Ed. Martins Fontes, 2016

HABERMAS, J. O Discurso Filosófico da Modernidade. Tradução de Luiz Sérgio Repa e Rodnei Nascimento. São Paulo: Ed. Martins Fontes, 2002a 
HABERMAS, J. Pensamento Pós-Metafísico: Estudos Filosóficos. Tradução de Flávio Beno Siebeneichler. Rio de Janeiro: Ed. Tempo Brasileiro, 2002b

JARRAT, S. Rereading the sophists: classical rhetoric refigured. Carbondale and Edwardsville: Southern Illinois University Press, 1991

KRAEMER, D. A good distance: Rawls and the new rhetoric project. Rhetoric Society Quaterly. v. 47, issue 1, 2017, pp. 81-98

KUZBORSKA, I. Rhetorical reading for writing strategies. Journal of ELT, 2019, pp. 1-7

LEMPEREUR, Alain. L’homme et la rhétorique. Paris: Méridiens Klincksieck, 1990.

LYOTARD, F. A Condição Pós-Moderna. Tradução de Ricardo Corrêa Barbosa. Rio de Janeiro: Ed. José Olympio, 2004

MAILLOUX, S. Reception histories: rhetoric, pragmatism, and american cultural politics. Ithaca and London: Cornell University Press, 1998

MARSILLAC, N. Racionalidade Retórica e Argumentativa. Revista Princípios. v. 18, n.30, 2011, pp. 271-291

MARSILLAC, N. Viragem Retórica, Viragem Pragmática e Superação da Metafísica. Revista Aufklärung. v.1, n. 2, 2014, pp. 165-180

MARSILLAC, N. Percepção ou Persuasão: Análise Retórica das Pré-Persuasões. Revista Rétor. v. 11, n. 1, 2021, pp. 1-24

MÖLLER, J. A Justiça como Equidade em John Rawls. Porto Alegre: Sérgio Antonio Fabris, 2006 NIETZSCHE, F. Da Retórica. Tradução de Tito Cardoso e Cunha. Lisboa; Ed. Presença, 1995

NIETZSCHE, F. Além do Bem e do Mal. Tradução de Paulo César de Souza. São Paulo: Companhia das Letras, 2005

PERELMAN, Chaim. Império Retórico. Tradução de Fernando Trindade e Rui Alexandre Grácio. Porto: Ed. Asa, 1993

PERELMAN, C. Ética e Direito. Tradução de Maria Ermantina Galvão G. Pereira. São Paulo: Ed. Martins Fontes, 1996

PERELMAN, C. OLBRECHTS-TYTECA, Lucie. Tratado da Argumentação: A Nova Retórica. Tradução de Maria Ermantina Galvão. São Paulo: Ed. Martins Fontes, 2002

PLEBE, Armando. Manual de Retórica. Tradução de Eduardo Brandão. São Paulo: Ed. Martins Fontes, 1992

QUONG, J. On the ideia of public reason, in: MANDLE, J. A Companion to Rawls. New Jersey; Ed. John Willey \& Sons, 2014

RAWLS, J. Liberalismo Político. Tradução de Sérgio René Madero Báez. Ciudad de México: Ed. UNAM, 1995 
RAWLS, J. Justiça e Democracia. Tradução de Irene Paternot. São Paulo: Ed. Martins Fontes, $2002^{\mathrm{a}}$

RAWLS, J. Uma Teoria da Justiça. Almiro Pisetta. São Paulo: Ed. Martins Fontes, 2002b

RAWLS, J. Justiça como Equidade. Tradução de Cláudia Berlinet. São Paulo: Ed. Martins Fontes, 2003

RAWLS, J. O Direito dos Povos. Tradução de Luis Carlos Borges. São Paulo: Ed. Martins Fontes, 2004

RORTY, R. Verdade e Progresso. Tradução de Denise R. Sales. Barueri, SP: Ed. Manole, 2005

RORTY, R. Objectivity, relativism, and truth. Cambridge: Cambridge University Press, 1991

SANTAYANA, G. Some turns of thought in modern philosophy. Whitefish: Kessinger Publishing, 2003

SCHIAPPA, Edward. Protágoras and logos: A study in greek philosophy and rhetoric. South Carolina:

University of South Carolina Press, 1991

SCHIAPPA, Edward. Defining reality: definitions and politics of meaning. Southern Illinois University Press, 2003

SCHOPENHAUER, A. A Arte de Ter Razão. Tradução de Camila Werner. São Paulo; Foro Editorial, 2014

SILLS, C. \& JENSEN, G. The philosophy of discourse: The rhetorical turn in twentieth-century. Portsmouth: Boynton/Cook Publishers, 1992

SWARTZ, O. Conducting socially responsible research: critical theory, neo-pragmatism, and rhetorical inquiry. California: Sage Publications, Inc, 1997

TOULMIN, S. Os Usos do Argumento. Tradução de Reinaldo Guarany. São Paulo; Ed. Martins Fontes, 2006

VATTIMO, G. O Fim da Modernidade: Niilismo e Hermenêutica na Cultura Pós-Moderna. Tradução de Eduardo Brandão. São Paulo. Ed. Martins Fontes, 2002

Trabalho recebido em 01 de outubro de 2021 Aceito em 02 de novembro de 2021 